\title{
Structure- and Potential-Dependent Cation Effects on CO Reduction at Copper Single-Crystal Electrodes
}

\author{
Elena Pérez-Gallent, Giulia Marcandalli, Marta Costa Figueiredo, Federico Calle-Vallejo, *,† \\ and Marc T. M. Koper*(1)
}

Leiden Institute of Chemistry, Leiden University, PO Box 9502, 2300 RA Leiden, The Netherlands

\section{Supporting Information}

ABSTRACT: The complexity of the electrocatalytic reduction of $\mathrm{CO}$ to $\mathrm{CH}_{4}$ and $\mathrm{C}_{2} \mathrm{H}_{4}$ on copper electrodes prevents a straightforward elucidation of the reaction mechanism and the design of new and better catalysts. Although structural and electrolyte effects have been separately studied, there are no reports on structure-sensitive cation effects on the catalyst's selectivity over a wide potential range. Therefore, we investigated $\mathrm{CO}$ reduction on $\mathrm{Cu}(100), \mathrm{Cu}(111)$, and $\mathrm{Cu}-$ (polycrystalline) electrodes in $0.1 \mathrm{M}$ alkaline hydroxide electrolytes ( $\mathrm{LiOH}, \mathrm{NaOH}, \mathrm{KOH}, \mathrm{RbOH}, \mathrm{CsOH}$ ) between 0 and $-1.5 \mathrm{~V}$ vs RHE. We used online electrochemical mass spectrometry and high-performance liquid chromatography to

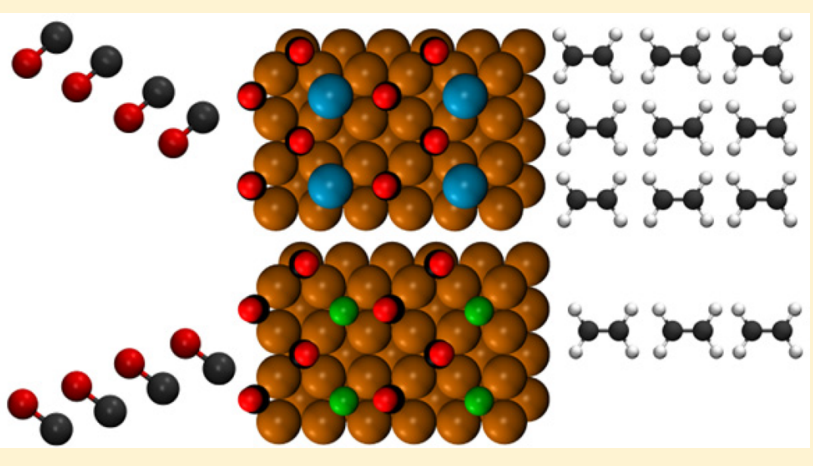
determine the product distribution as a function of electrode structure, cation size, and applied potential. First, cation effects are potential dependent, as larger cations increase the selectivity of all electrodes toward ethylene at $E>-0.45 \mathrm{~V}$ vs RHE, but methane is favored at more negative potentials. Second, cation effects are structure-sensitive, as the onset potential for $\mathrm{C}_{2} \mathrm{H}_{4}$ formation depends on the electrode structure and cation size, whereas that for $\mathrm{CH}_{4}$ does not. Fourier Transform infrared spectroscopy (FTIR) and density functional theory help to understand how cations favor ethylene over methane at low overpotentials on $\mathrm{Cu}(100)$. The rate-determining step to methane and ethylene formation is $\mathrm{CO}$ hydrogenation, which is considerably easier in the presence of alkaline cations for a CO dimer compared to a $\mathrm{CO}$ monomer. For $\mathrm{Li}^{+}$and $\mathrm{Na}^{+}$, the stabilization is such that hydrogenated dimers are observable with FTIR at low overpotentials. Thus, potential-dependent, structure-sensitive cation effects help steer the selectivity toward specific products.

\section{INTRODUCTION}

Electrocatalytic reduction of $\mathrm{CO}_{2}$ is an attractive strategy for the conversion of renewable energy into fuels, which helps in closing the biogeochemical carbon cycle. Several metals and other types of electrodes have been studied for the electrochemical reduction of $\mathrm{CO}_{2}{ }^{1}$ However, copper remains the only metal to produce hydrocarbons (primarily methane and ethylene) with reasonable faradaic efficiencies. ${ }^{2,3}$ For instance, Jaramillo et al. reported the formation of 16 different species from $\mathrm{CO}_{2}$ reduction in aqueous bicarbonate solution, where complex molecules including $\mathrm{C}_{2}$ (e.g., acetaldehyde, acetate, ethylene glycol, glycolaldehyde) and $\mathrm{C}_{3}$ species (e.g., $n$ propanol, propionaldehyde, allyl alcohol, acetone) were detected with current efficiencies lower than 5\%. ${ }^{4}$ Several studies of Cu-based catalysts ${ }^{5,6}$ have shown higher selectivity for $\mathrm{C}_{2}$ products. However, the mechanistic reasons for their selectivity remain elusive. Here we examine the combined role of electrolyte cations, potential window, and catalyst structure on the selectivity toward $\mathrm{C}_{1}$ vs $\mathrm{C}_{2}$ products during $\mathrm{CO}$ reduction on $\mathrm{Cu}$.

Hori et al. showed that $\mathrm{CO}_{2}$ reduction on $\mathrm{Cu}$ electrodes is structure sensitive: ${ }^{7} \mathrm{Cu}(100)$ electrodes are most efficient for the conversion of $\mathrm{CO}_{2}$ to $\mathrm{C}_{2} \mathrm{H}_{4}, \mathrm{Cu}(111)$ favors the formation of $\mathrm{CH}_{4}$ and $\mathrm{HCOOH}$, and $\mathrm{Cu}(110)$ gives the highest current efficiencies for secondary $\mathrm{C}_{2}$ products (e.g., acetic acid, acetaldehyde, and ethanol). Similar results were obtained by Schouten et al. during the reduction of $\mathrm{CO} .{ }^{8}$ While Hori et al. concluded that the introduction of steps on (100) terraces enhances $\mathrm{C}_{2} \mathrm{H}_{4}$ evolution and suppresses $\mathrm{CH}_{4}$ formation,? Schouten et al. attributed the selective formation of $\mathrm{C}_{2} \mathrm{H}_{4}$ to pristine (100) terraces. ${ }^{8}$ Moreover, they showed that $\mathrm{CO}$ reduction to $\mathrm{C}_{2} \mathrm{H}_{4}$ takes place preferentially at $\mathrm{Cu}(100)$ electrodes without simultaneous $\mathrm{CH}_{4}$ evolution, which indicates that the reaction paths toward $\mathrm{CH}_{4}$ and $\mathrm{C}_{2} \mathrm{H}_{4}$ bifurcate in the early stages of $\mathrm{CO}$ reduction. ${ }^{9}$ On the other hand, it has been shown that $\mathrm{C}_{2}$ species such as ethylene and ethanol are formed in a common pathway that bifurcates at the late stages of the reaction. ${ }^{10-12}$ The favorable formation of $\mathrm{C}_{2} \mathrm{H}_{4}$ on $\mathrm{Cu}(100)$ is supported by density functional theory (DFT) calculations, which demonstrate that $\mathrm{C}-\mathrm{C}$ bond formation proceeds via $\mathrm{CO}$ dimerization and has a lower activation barrier on $\mathrm{Cu}(100)$ than on $\mathrm{Cu}(111) \cdot{ }^{13,14}$ In addition to structural effects, there is an important role of the

Received: September 23, 2017

Published: October 24, 2017 

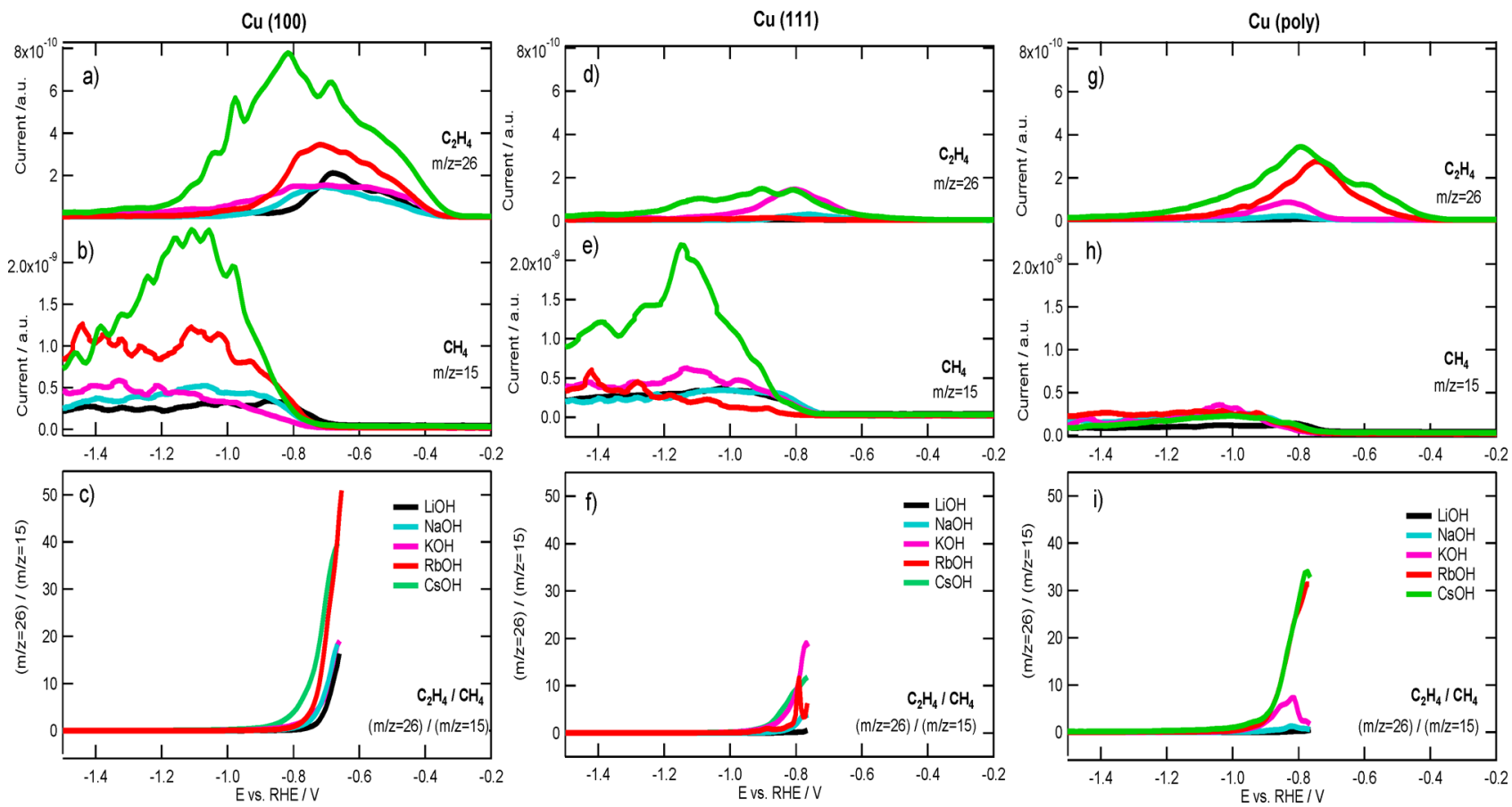

Figure 1. OLEMS mass fragments measured during $\mathrm{CO}$ reduction associated with the formation of $\mathrm{C}_{2} \mathrm{H}_{4}$ (top panel, a, d, and $\mathrm{g}$ ) and $\mathrm{CH}_{4}(\mathrm{middle}$ panel, b, e, and h) on (a) $\mathrm{Cu}(100)$, (b) $\mathrm{Cu}(111)$, and (c) polycrystalline $\mathrm{Cu}$ for different $0.1 \mathrm{M}$ alkaline hydroxide solutions. Bottom panel (c, f, and i) shows the potential-dependent ratio $(\mathrm{m} / z=26) /(\mathrm{m} / z=15)$ of OLEMS mass fragments associated with the formation of $\mathrm{C}_{2} \mathrm{H}_{4}$ and $\mathrm{CH}_{4}$ during $\mathrm{CO}$ reduction.

electrolyte, especially through the $\mathrm{pH}$. The onset potential on the NHE scale of $\mathrm{CH}_{4}$ evolution depends on $\mathrm{pH}$, while $\mathrm{C}_{2} \mathrm{H}_{4}$ evolution does not. Hori et al. concluded that $\mathrm{CO}$ reduction to $\mathrm{CH}_{4}$ proceeds as a series of concerted proton-electron transfers, in contrast with $\mathrm{C}_{2} \mathrm{H}_{4}$ evolution, for which the ratelimiting step involves only an early electron transfer, justifying its $\mathrm{pH}$-independent onset. ${ }^{15,16}$ We showed previously with DFT calculations that the electron transfer to form a negatively charged $(\mathrm{CO})_{2}$ dimer is the potential-limiting step of $\mathrm{CO}$ reduction to $\mathrm{C}_{2} \mathrm{H}_{4}$ on $\mathrm{Cu}(100),{ }^{11}$ in contrast with studies that assume only concerted proton-electron transfers, ${ }^{17}$ which cannot explain the $\mathrm{pH}$ independence of $\mathrm{C}_{2} \mathrm{H}_{4}$ formation.

In addition to $\mathrm{pH}$, the activity and selectivity of $\mathrm{Cu}$ for $\mathrm{CO}_{2}$ reduction also depends on the nature of the anions and/or cations in the electrolyte. Strasser et al. showed that the selectivity of the major products of $\mathrm{CO}_{2}$ reduction depends on the size and concentration of halides: ${ }^{18}$ while $\mathrm{Cl}^{-}$and $\mathrm{Br}^{-}$ enhance the production of $\mathrm{CO}, \mathrm{I}^{-}$lowers $\mathrm{CO}$ evolution and increases the selectivity toward methane. The effects were attributed to halide adsorption on copper, which alters the negative charge on the surface and favors the protonation of $\mathrm{CO}$ toward $\mathrm{CH}_{4}$. Furthermore, Lee et al. showed that the presence of $\mathrm{Cl}^{-}$enhances the catalytic activity toward multiple $\mathrm{C}_{2}-\mathrm{C}_{4}$ species on $\mathrm{Cu}$-oxide-derived catalysts, due to the presumed advantageous affinity between reaction intermediates and catalytic surface in the presence of $\mathrm{Cl}^{-}{ }^{19}$ Hori et al. reported that alkaline cations affect the selectivity of $\mathrm{CO}_{2}$ and $\mathrm{CO}$ reduction on polycrystalline copper, ${ }^{10}$ so that larger cations favor the formation of $\mathrm{C}_{2}$ and $\mathrm{C}_{3}$ species such as $\mathrm{C}_{2} \mathrm{H}_{4}$, $\mathrm{C}_{2} \mathrm{H}_{5} \mathrm{OH}$, and $\mathrm{C}_{3} \mathrm{H}_{7} \mathrm{OH}$. Cation effects were explained by Hori et al. in terms of a variation in the potential in the outer Helmholtz plane (OHP), which originates from a difference in the hydration number of the different cations. Larger cations are less hydrated and expected to adsorb more easily on the cathode surface, shifting the potential to more positive values, thereby steering the selectivity toward $\mathrm{C}_{2} \mathrm{H}_{4}$ instead of $\mathrm{CH}_{4}$. Such experimental observations were confirmed by Kyriacou et al. ${ }^{20}$ Bell and co-workers explained cation effects on $\mathrm{CO}_{2}$ reduction in terms of the different $\mathrm{p} K_{\mathrm{a}}$ values for cation hydrolysis, which lower the local $\mathrm{pH}$ at the surface from $\mathrm{Li}^{+}$to $\mathrm{Cs}^{+}$and lead to an increase in $\mathrm{CO}_{2}$ concentration near the electrode surface. ${ }^{21}$ However, this model cannot explain the fact that similar cation effects are observed during $\mathrm{CO}$ reduction, ${ }^{10}$ the concentration of which is not affected by $\mathrm{pH}$.

All previous studies concerning cation effects in the reduction of $\mathrm{CO}_{2}$ and $\mathrm{CO}$ on copper have used only polycrystalline electrodes and did not cast light on their potential dependence. In the following, we will argue that such effects depend on the electrode structure, the applied potential, and the size of the cation. To this end, we used two singlecrystalline copper surfaces $(\mathrm{Cu}(100), \mathrm{Cu}(111))$ together with polycrystalline $\mathrm{Cu}$ in $\mathrm{LiOH}, \mathrm{NaOH}, \mathrm{KOH}, \mathrm{RbOH}$, and $\mathrm{CsOH}$ solutions. Online electrochemical mass spectrometry (OLEMS) and high-performance liquid chromatography (HPLC) were used to investigate the product distribution over a wide potential range. In addition, in situ Fourier transform infrared (FTIR) spectroscopy and DFT calculations are used to identify early reaction intermediates of $\mathrm{CO}$ reduction on $\mathrm{Cu}(100)$ and explain the cation-mediated enhancement of ethylene formation over methane. Understanding how the structure- and potential-dependent cation effects impact the catalytic performance provides insight for devising efficient and selective catalysts for $\mathrm{CO}$ reduction.

\section{RESULTS AND DISCUSSION}

2.1. OLEMS and HPLC. $\mathrm{Cu}(111), \mathrm{Cu}(100)$, and $\mathrm{Cu}$ (poly) were characterized by voltammetry before and after experiments to control the morphology of the surface; ${ }^{22}$ see Figure 
S8. The activity and selectivity of the three electrodes toward CO reduction were investigated with OLEMS by varying the alkaline cation in the $0.1 \mathrm{M}$ hydroxide supporting electrolyte. A linear sweep voltammetry between 0 and $-1.5 \mathrm{~V}$ vs RHE at a scan rate of $1 \mathrm{mV} \mathrm{s}^{-1}$ was carried out while simultaneously the volatile products were detected with OLEMS. Figure 1 displays the volatile products formed during the reduction of $\mathrm{CO}$ on $\mathrm{Cu}(100), \mathrm{Cu}(111)$, and polycrystalline $\mathrm{Cu}$ for different alkaline hydroxide solutions of identical concentration $(0.1 \mathrm{M})$. Figure $1 \mathrm{a}-\mathrm{c}$ show the results of $\mathrm{CO}$ reduction for $\mathrm{Cu}(100)$. The middle panel (b) shows the mass fragment $\mathrm{m} / z=15$ associated with $\mathrm{CH}_{4}$, and the top panel (a) shows the mass fragment $\mathrm{m} / \mathrm{z}$ $=26$ associated with $\mathrm{C}_{2} \mathrm{H}_{4}$. It is important to note that the reported amounts of products formed are in fact lower than the amounts expected if a purification process of the electrolyte would have been performed, according to the results obtained by Surendranath. ${ }^{23}$ The onset potential for $\mathrm{CH}_{4}$ at ca. $-0.65 \mathrm{~V}$ is independent of the cation in solution. For all cations, except $\mathrm{Cs}^{+}$, the formation of methane reaches a plateau around $-0.9 \mathrm{~V}$ vs RHE. The general trend is that larger cations increase methane production. Figure $1 \mathrm{~b}$ also shows that the formation of $\mathrm{C}_{2} \mathrm{H}_{4}$ on $\mathrm{Cu}(100)$ starts at ca. $-0.3 \mathrm{~V}$ regardless of the cation. The amount of ethylene formed, as well as its formation rate, increases with the size of the cation. Especially $\mathrm{Cs}^{+}$shows a significant increase in ethylene production.

On $\mathrm{Cu}(111)$ (Figure $1 \mathrm{~d}-\mathrm{f}$ ), the onset potential for $\mathrm{CH}_{4}$ is ca. $-0.65 \mathrm{~V}$ regardless of the cation, with trends in activity similar to $\mathrm{Cu}(100)$. ( $\mathrm{Rb}^{+}$deviates from this trend, but, as mentioned in Section S7 in the SI, RbOH frequently showed problems with purity and reproducibility.) The formation of $\mathrm{C}_{2} \mathrm{H}_{4}$ starts around $-0.4 \mathrm{~V}$ regardless of the cation, which is 0.1 $\mathrm{V}$ more negative than on $\mathrm{Cu}(100)$. The amount of ethylene formed, as well as its formation rate, is highest with $\mathrm{Cs}^{+}$in the electrolyte. It is important to point out the differences observed with the previous work by Schouten et al., ${ }^{9}$ where the formation of ethylene and methane on $\mathrm{Cu}(111)$ displayed a similar profile both having an onset potential of approximately $-0.8 \mathrm{~V}$. Similar results were obtained by Nilsson et al., ${ }^{5}$ who found onset potentials for methane and ethylene on $\mathrm{Cu}(111)$ close to -0.9 $\mathrm{V}$. However, in this work ethylene formation on $\mathrm{Cu}(111)$ starts at lower overpotentials $(-0.4$ to $-0.5 \mathrm{~V})$, which we attribute to the higher sensitivity achieved by using a larger OLEMS tip in combination with the nonmeniscus configuration. Although it is not possible to rule out the contribution of other facets present on the electrode, the significantly higher activity and lower onset potential of $\mathrm{Cu}(100)$ surface for ethylene formation is also clearly observed in this work.

On polycrystalline $\mathrm{Cu}$ (Figure $1 \mathrm{~g}-\mathrm{i}$ ) the onset potential for $\mathrm{CH}_{4}$ production is around $-0.65 \mathrm{~V}$ regardless of the cation in solution. The plateau is less pronounced than on the single crystals, and the trend with the size of the cation is less evident. $\mathrm{C}_{2} \mathrm{H}_{4}$ formation is strongly dependent on the cation, with the smallest cation $\left(\mathrm{Li}^{+}\right)$showing essentially no ethylene formation and the largest cation $\mathrm{Cs}^{+}$showing the strongest selectivity toward ethylene. Although we remark again that it is currently impossible to perform fully quantitative selectivity measurements using OLEMS, the results in Figure 1 allow us to conclude that (i) larger cations enhance $\mathrm{CO}$ reduction to ethylene at low overpotentials and the effect is significantly stronger on $\mathrm{Cu}(100)$ and (ii) larger cations enhance methane production at high overpotentials.

To support these conclusions, we consider in Figure 1 bottom panels ( $c, f$, and $i)$ the potential dependence of the ratio of the mass signals corresponding to ethylene $(m / z=26)$ and methane $(m / z=15)$ for the three different $\mathrm{Cu}$ electrodes. The ratio was plotted as $I(m / z=26) / I(m / z=15)$, so a high value expresses a larger production of ethylene over methane. Since at potentials more positive than $-0.65 \mathrm{~V}$ there is no methane production and the value of the ratio $C_{2} / C_{1}$ is infinite, the ratio was only calculated in the potential region where both products coexist or the amount of $\mathrm{C}_{2} \mathrm{H}_{4}$ detected is null. At low overpotentials, all copper surfaces show a higher selectivity toward ethylene with increasing cation radius, with the highest selectivity achieved for $\mathrm{Cu}(100)$, especially with $\mathrm{Rb}^{+}$and $\mathrm{Cs}^{+}$in solution. In particular, for a fixed potential of $-0.75 \mathrm{~V}$, the ethylene/methane ratio for $\mathrm{Cu}(100)$ is 1.59 for $\mathrm{Li}^{+}, 3.93$ for $\mathrm{Na}^{+}, 4.32$ for $\mathrm{K}^{+}, 7.54$ for $\mathrm{Rb}^{+}$, and 14.8 for $\mathrm{Cs}^{+}$(see Figure S2a). These values show a clear cation effect toward ethylene formation that monotonically follows the cation sizes. In addition, the selectivity for ethylene is enhanced in a larger potential range when larger cations are in solution. Figure $S 2 b$ shows that larger cations maintain the same selectivity for ethylene at more negative potentials compared to smaller cations: the potentials for which a fixed value of 5 for the ethylene/methane ratio are $-0.70,-0.72,-0.72,-0.74$, and $-0.79 \mathrm{~V}_{\text {for }} \mathrm{Li}^{+}, \mathrm{Na}^{+}, \mathrm{K}^{+}, \mathrm{Rb}^{+}$, and $\mathrm{Cs}^{+}$. Similar tendencies are observed for $\mathrm{Cu}(111)$ and polycrystalline $\mathrm{Cu}$ but with significantly lower ratios. The ratio $\mathrm{C}_{2} / \mathrm{C}_{1}$ on $\mathrm{Cu}(111)$ and polycrystalline $\mathrm{Cu}$ in $\mathrm{LiOH}$ solution is almost zero over the whole potential range in which both species coexist, indicating low selectivity for ethylene formation over methane in this electrolyte.

Figure $S 1$ shows the mass fragment $m / z=2$ associated with the formation of $\mathrm{H}_{2}$ from the competitive hydrogen evolution reaction (HER). For all copper surfaces, hydrogen evolution starts at ca. $-0.4 \mathrm{~V}$ for all different cations except $\mathrm{Cs}^{+}$, for which it starts at slightly less negative potentials. The amount of hydrogen produced as well as its formation rate increases with the size of the cation in the electrolyte for all copper electrodes.

The minor liquid products obtained during CO reduction on polycrystalline copper and their dependence on the nature of the cation were collected and analyzed with HPLC. Due to the low amount of products formed, chronoamperometry experiments for $2 \mathrm{~h}$ were carried out using a large copper disk (16.85 $\mathrm{mm}$ diameter). Given the long duration of this set of experiments, we did not perform these experiments with single-crystal electrodes, since the stability of the surface structure may be compromised. Chronoamperometry experiments were carried out at three different potentials, $-0.5,-0.7$, and $-0.9 \mathrm{~V}$ vs RHE, with different alkaline hydroxides. The concentrations of the obtained products and their cation dependence are summarized in Figure S3. The only liquid product detected for $\mathrm{CO}$ reduction at $-0.5 \mathrm{~V}$ was formic acid. At more negative potentials $(-0.7$ and $-0.9 \mathrm{~V})$ the products obtained were formic acid as a $\mathrm{C}_{1}$ product; acetic acid, glycolic acid, ethylene glycol, and ethanol as $\mathrm{C}_{2}$ products; and propionaldehyde, 1-propanol, and allyl alcohol as $\mathrm{C}_{3}$ products. Such $\mathrm{C}_{2}$ and $\mathrm{C}_{3}$ products obtained during $\mathrm{CO}$ reduction have been reported previously. ${ }^{4,24}$ In general, larger cations such as $\mathrm{Cs}^{+}$promote $\mathrm{CO}$ reduction to $\mathrm{C}_{2+}$ compounds compared to small cations $\left(\mathrm{Li}^{+}\right.$and $\left.\mathrm{Na}^{+}\right)$, in agreement with the results of Hori et al. ${ }^{10}$ A detailed description of the concentration of the products depending on the cation in solution can be found in the SI, section S2.

Further analysis by ${ }^{1} \mathrm{H}$ NMR was carried out for the samples obtained after $2 \mathrm{~h}$ of chronoamperometry at $-0.9 \mathrm{~V}$ with $\mathrm{Na}$-, 
a) $\mathrm{Cu}(100), 0.1 \mathrm{M} \mathrm{LiOH}, \mathrm{CO}$ atmosphere b) $\mathrm{Cu}(100), 0.1 \mathrm{M} \mathrm{NaOH}, \mathrm{CO}$ atmosphere c) $\mathrm{Cu}(100), 0.1 \mathrm{M} \mathrm{KOH}, \mathrm{CO}$ atmosphere

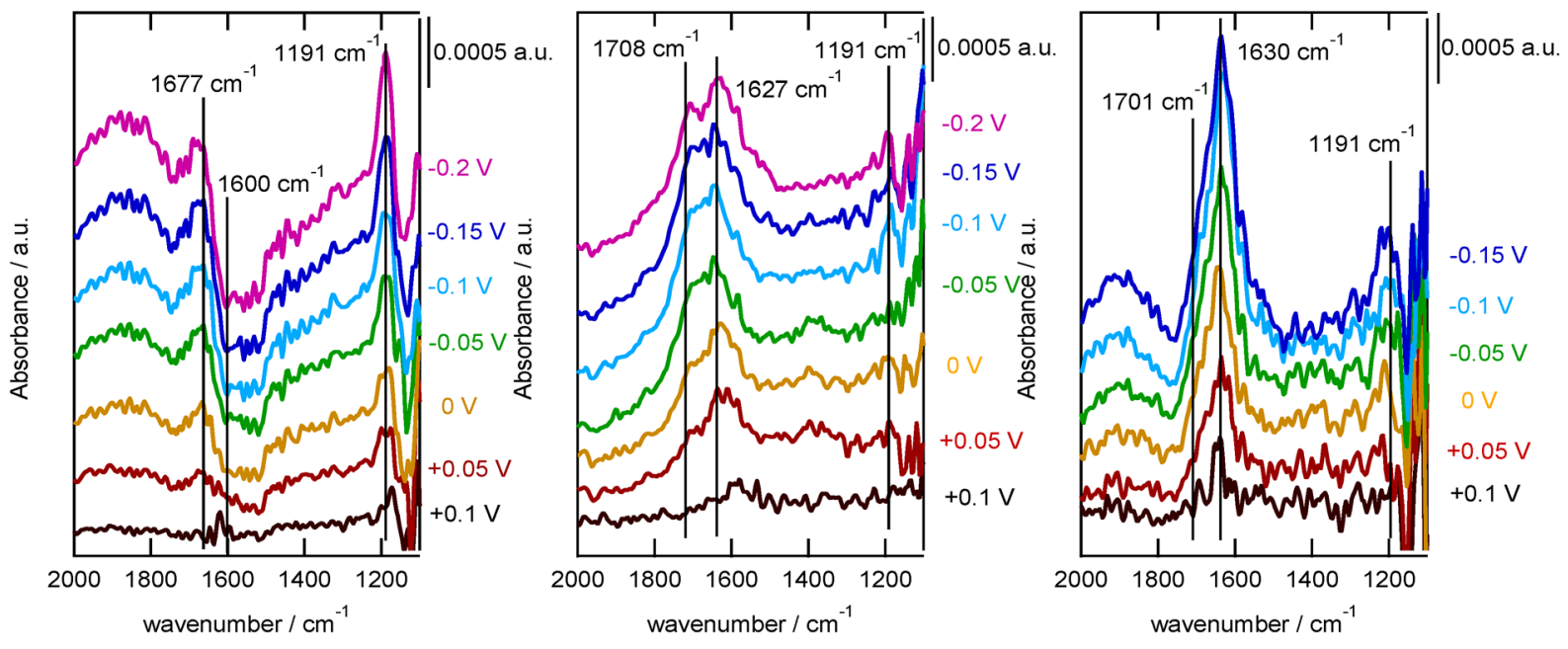

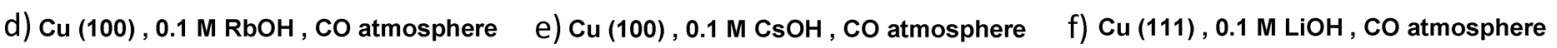

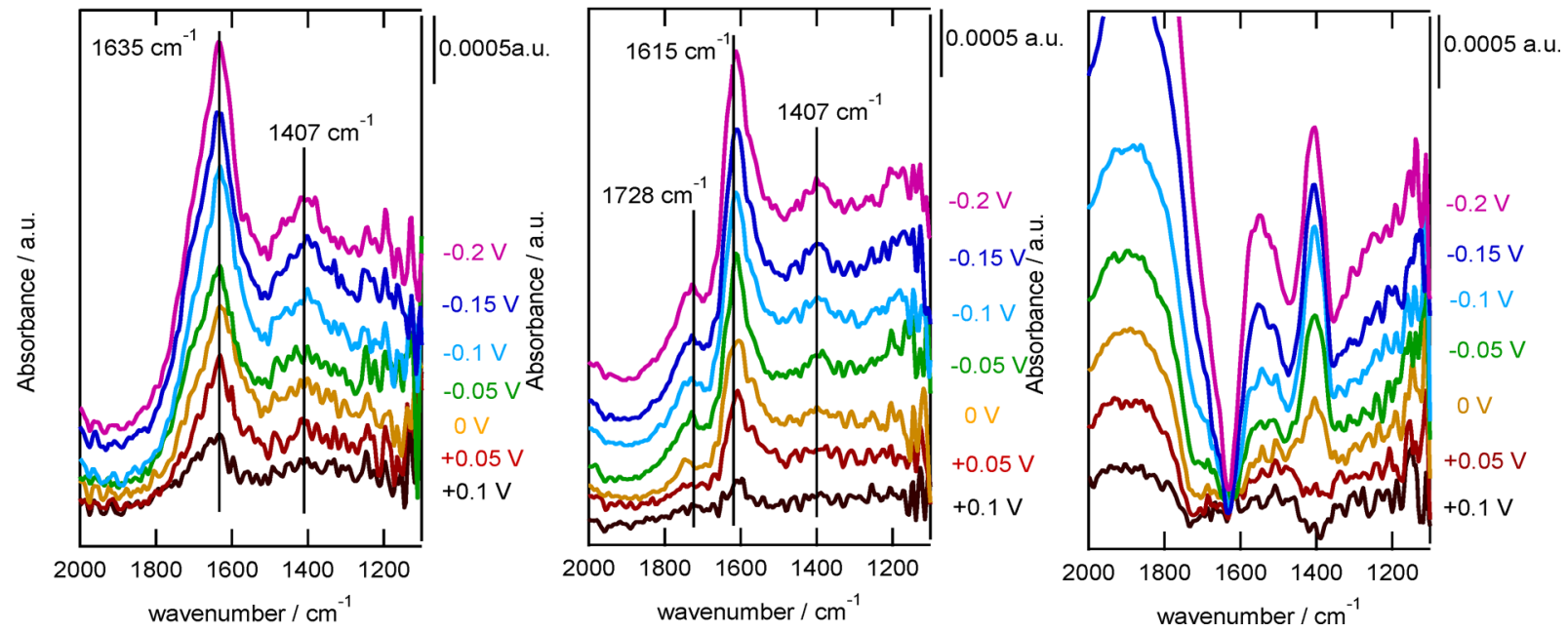

Figure 2. Potential-dependent absorbance spectra of $\mathrm{Cu}(100)$ in a $\mathrm{CO}$ atmosphere in a $0.1 \mathrm{M}$ solution of (a) $\mathrm{LiOH},(\mathrm{b}) \mathrm{NaOH},(\mathrm{c}) \mathrm{KOH},(\mathrm{d})$ $\mathrm{RbOH}$, and (e) $\mathrm{CsOH}$. (f) $\mathrm{LiOH}$ on $\mathrm{Cu}(111)$, provided for comparison. Reference spectrum recorded at $+0.1 \mathrm{~V}$ vs RHE.

$\mathrm{K}$ - and Cs-containing electrolytes (Figure S4 in the SI). The ${ }^{1} \mathrm{H}$ NMR spectra confirmed the products detected with HPLC and their higher concentration with $\mathrm{K}^{+}$and $\mathrm{Cs}^{+}$compared to $\mathrm{Na}^{+}$. In addition, methanol was also detected as a reduction product of $\mathrm{CO}$ for those three cations. Identification of methanol was not possible with HPLC due to an overlap with the intense peaks of the eluent.

Note that we were unable to consistently detect aldehydes as products, while acetaldehyde and propionaldehyde have been reported to be products of $\mathrm{CO}_{2}$ reduction on copper. ${ }^{4}$ This is probably due to the fact that our experiments were carried out

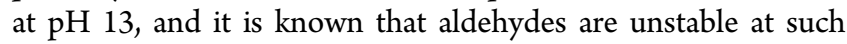
high $\mathrm{pH}$ and disproportionate following a Cannizzaro reaction, giving the corresponding carboxylic acid and alcohol. ${ }^{25}$

2.2. FTIR. FTIR spectra were recorded during the early stages of $\mathrm{CO}$ reduction on $\mathrm{Cu}(100)$ and $\mathrm{Cu}(111)$ in different alkaline hydroxide solutions, to gain insight into the dependence of the reaction mechanism on the surface structure of the electrode as well as the cation in the electrolyte. Recent FTIR experiments carried out in Li-containing electrolytes in our group indicated a structure-sensitive process in the early stages of CO reduction, ${ }^{26}$ which together with DFT calculations led us to hypothesize the formation of a hydrogenated $\mathrm{CO}$ dimer intermediate in the pathway leading to ethylene, in agreement with previous experimental ${ }^{8}$ and theoretical ${ }^{13}$ studies. Figure $2 \mathrm{a}-\mathrm{f}$ show the potential-dependent absorbance spectra of $\mathrm{Cu}(100)$ and $\mathrm{Cu}(111)$ under a $\mathrm{CO}$ atmosphere for different 0.1 $\mathrm{M}$ alkaline hydroxide solutions. The spectra recorded on $\mathrm{Cu}(100)$ in $\mathrm{LiOH}$ solution were previously reported by our group. $^{26}$

The reference spectrum was taken at $+0.1 \mathrm{~V}$ vs RHE, and additional spectra are provided for $+0.05,0.00,-0.05,-0.10$, -0.15 , and $-0.2 \mathrm{~V}$ vs RHE. Due to experimental limitations, it was not possible to record spectra at more negative potentials where the hydrogen evolution reaction starts, as this destabilizes the thin layer formed between the electrode and the prism of the spectrometer, resulting in unstable spectra. These limitations are further explained in section S7 of the Supporting Information. CO reduction in different alkaline hydroxide solutions was also studied on $\mathrm{Cu}(111)$ (a representative spectrum is shown in Figure 2f). The FTIR spectra for $\mathrm{CO}$ interacting with $\mathrm{Cu}(100)$ exhibit two common bands for all alkaline electrolytes. The first band, in the range of $1635-1600 \mathrm{~cm}^{-1}$, corresponds to the $\mathrm{O}-\mathrm{H}$ bending mode of 
$\mathrm{H}_{2} \mathrm{O}$. This band causes fluctuations in the baseline of the spectra, making it difficult to identify other bands in this wavenumber range. The second band, in the range of 1730$1670 \mathrm{~cm}^{-1}$, corresponds to the $\mathrm{C}-\mathrm{O}$ stretching ${ }^{27-29}$ of $\mathrm{CO}$ adsorbed on hollow sites on $\mathrm{Cu}(100) .{ }^{30-33}$ Apart from these two bands, two other bands arise depending on the electrolyte used. For $\mathrm{Li}, \mathrm{Na}$, and $\mathrm{K}$ hydroxides, a band at $1191 \mathrm{~cm}^{-1}$ attributed to the $\mathrm{C}-\mathrm{O}$ stretching of a hydrogenated dimer $(\mathrm{OCCOH})^{26}$ is observed. Note that the assignment of this band to the hydrogenated dimer and the exclusion of other species were discussed extensively in our previous paper. ${ }^{26}$ Besides, in section S8 in the SI we also provide arguments to discard the presence of oxalates. In contrast, the band at 1191 $\mathrm{cm}^{-1}$ is not observed when $\mathrm{Rb}^{+}$and $\mathrm{Cs}^{+}$are in solution, a feature that will be explained in the next section with DFT calculations. The intensity of the band assigned to $\mathrm{C}-\mathrm{O}$ stretching of the hydrogenated dimer diminishes from $\mathrm{Li}$ to $\mathrm{K}$ (Figure 2a-c). For Rb and Cs (Figure 2d,e), a band at 1407 $\mathrm{cm}^{-1}$ is observed, which according to the transmission spectra obtained for various species in solution might correspond to formaldehyde. Formaldehyde has been suggested to be an intermediate of the reduction of $\mathrm{CO}$ to $\mathrm{CH}_{4}$ on $\mathrm{Cu}(211){ }^{34,35}$ The spectra obtained during the reduction of $\mathrm{CO}$ on $\mathrm{Cu}(111)$ (Figure 2f) also show the band at $1407 \mathrm{~cm}^{-1}$. However, on $\mathrm{Cu}(111)$ this band is more intense for smaller cations than for larger cations.

2.3. DFT Calculations. To rationalize some of the observed cation effects, we resort now to DFT calculations. We will focus on $\mathrm{Cu}(100)$, as ethylene is formed at low overpotentials and the FTIR results in Figure 2 suggest the presence of a hydrogenated dimer intermediate. Since CO hydrogenation is critical for both methane ${ }^{17}$ and ethylene production, ${ }^{11,36}$ in the following we will focus only on this step. Figure 3 shows the energetics of the first electrochemical steps in the reduction of one $\mathrm{CO}$ molecule to $\mathrm{C}_{1}$ species and two $\mathrm{CO}$ molecules to $\mathrm{C}_{2}$ species in a vacuum and in the presence of $\mathrm{Li}, \mathrm{Na}$, and $\mathrm{Cs}$ (the energies shown are the averages of the separate values found for the three cations; for details see Figures S11 and S12). The first proton-electron transfer for a single $\mathrm{CO}$ molecule proceeds as

$$
*+\mathrm{CO}(\mathrm{g})+\mathrm{H}^{+}+\mathrm{e}^{-} \rightarrow * \mathrm{CHO}
$$

This step consists of $\mathrm{CO}$ adsorption and hydrogenation. On the other hand, the first proton-electron transfer for two $\mathrm{CO}$ molecules proceeds as

$$
*+2 \mathrm{CO}(\mathrm{g})+\mathrm{H}^{+}+\mathrm{e}^{-} \rightarrow * \mathrm{OCCOH}
$$

This step comprises successive $\mathrm{CO}$ adsorption (denoted *CO and $2 * \mathrm{CO}$ in Figure 3 ), dimerization (*OCCO), and hydrogenation $(* \mathrm{OCCOH})$. The adsorption configurations of $\mathrm{C}_{1}$ and $\mathrm{C}_{2}$ species are provided in Figures S9 and S10.

From Figure 3 it is clear that all intermediates, namely, $* \mathrm{CO}$, $2 * \mathrm{CO}, * \mathrm{OCCO}, * \mathrm{CHO}$, and $* \mathrm{OCCOH}$, are significantly stabilized by the presence of the alkaline cations, but the strength of the effect depends on the particular adsorbate. Essentially, the overall cation effect is due to the larger stabilization of adsorbates containing $\mathrm{C}-\mathrm{C}$ bonds (*OCCO and $* \mathrm{OCCOH})$ with respect to the $\mathrm{C}_{1}$ adsorbates $(* \mathrm{CO}$, $2 * \mathrm{CO}, * \mathrm{CHO})$. Importantly, the presence of the cations changes the binding mode of the $\mathrm{CO}$ dimer, as shown in Figure S9, and the adsorption sites of the adsorbates (Figures S9 and S10).

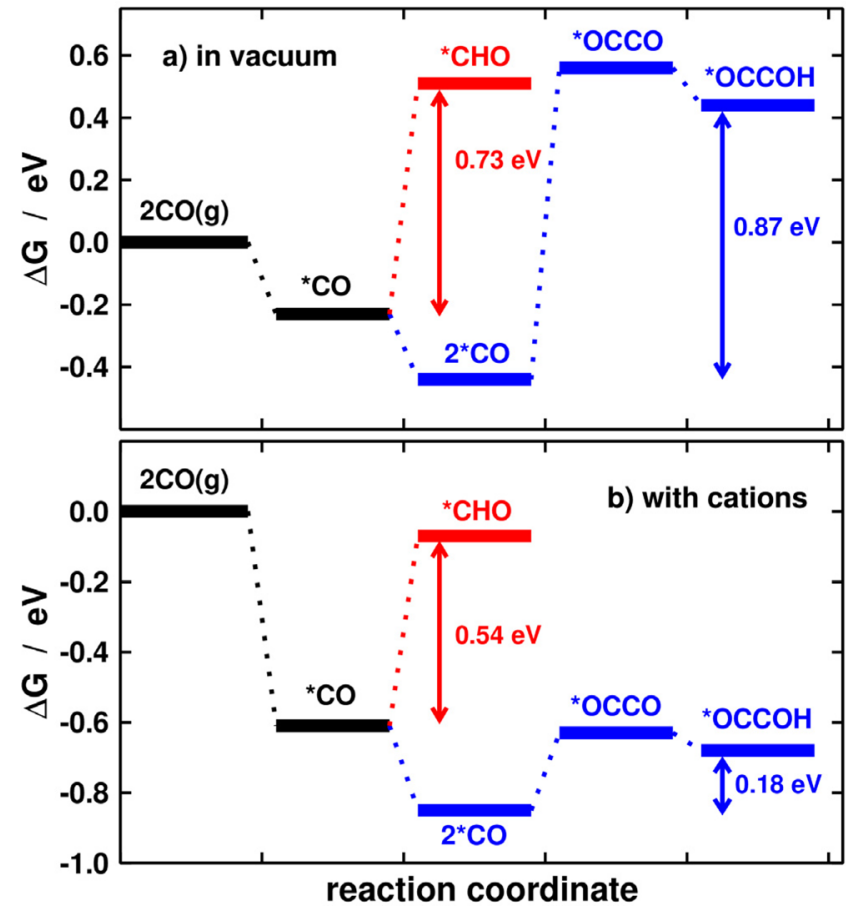

Figure 3. Energetics of the first electrochemical steps of $\mathrm{CO}$ reduction for the $C_{1}$ and $C_{2}$ pathways on $\mathrm{Cu}(100)$ at $0 \mathrm{~V}$ vs RHE. (a) In a vacuum and (b) with cations, averaging the energies for $\mathrm{Li}, \mathrm{Na}$, and $\mathrm{Cs}$ in Figures S11 and S12. While in a vacuum both pathways are highly endothermic, the $\mathrm{C}_{2}$ pathway is remarkably promoted by alkaline cations.

Note that both steps described by eqs 1 and 2 are highly endothermic in the absence of cations, so that the reaction energies for $* \mathrm{CO}$ hydrogenation are 0.73 and $0.87 \mathrm{eV}$ for the $\mathrm{C}_{1}$ and $\mathrm{C}_{2}$ pathways (see Tables S2 and S3). In the presence of the cations, the energetics of $* \mathrm{CO}$ hydrogenation are lowered from $0.73 \mathrm{eV}$ to $0.54 \mathrm{eV}$. This change is dwarfed by the dramatic lowering in the $\mathrm{C}_{2}$ pathway from $0.87 \mathrm{eV}$ to $0.18 \mathrm{eV}$. This attests to a substantial enhancing effect of the alkaline cations by decreasing the energy barriers for $* \mathrm{CO}$ reductive coupling. The enhancement of $* \mathrm{OCCO}$ with respect to $2 * \mathrm{CO}$ clearly illustrates cation effects: the adsorption energy of * OCCO is made more negative by the cations by $\sim 1.2 \mathrm{eV}$, whereas the adsorption energy of $2 * \mathrm{CO}$ is stabilized by $\sim 0.4$ $\mathrm{eV}$. In sum, Figure $3 \mathrm{~b}$ explains well the experimentally observed preference of $\mathrm{Cu}(100)$ for ethylene formation over methane.

There is also another manifestation of the cation effect, related to the stability of $* \mathrm{OCCOH}$. Similar to the dimer, the hydrogenated counterpart is significantly stabilized $(1.16 \mathrm{eV}$ on average) by the presence of alkaline cations. Following the model of Nørskov et al. ${ }^{17}$ in which the onset potential is linked to the largest uphill reaction energy in a given pathway, the potential to go from $2 * \mathrm{CO}$ to $* \mathrm{OCCOH}$ is $-0.10 \mathrm{~V}$ for $\mathrm{Li}^{+}$, -0.16 for $\mathrm{Na}^{+}$, and $-0.28 \mathrm{eV}$ for $\mathrm{Cs}^{+}$(see Figure S12). Therefore, the hydrogenated dimer should only be observable with FTIR at low potentials $(>-0.2 \mathrm{~V})$ in the presence of $\mathrm{Li}^{+}$ and $\mathrm{Na}^{+}$, but not in the case of $\mathrm{Cs}^{+}$, in agreement with the experimental results in Figure 2. This shows that cation effects can be averaged to observe overall trends, but important subtleties pertaining to each cation can only be captured by separate analyses. In addition to the quantitative considerations on the cation effect provided in Figure 3, in section S6 in the SI 
we also discuss some qualitative features of $\mathrm{Li}^{+}, \mathrm{Na}^{+}$, and $\mathrm{Cs}^{+}$ coadsorption with $\mathrm{C}_{1}$ and $\mathrm{C}_{2}$ species.

2.4. Mechanistic Implications. The OLEMS results in Figure 1 suggest a relation between $m / z=15$ and $m / z=26$ (associated with methane and ethylene formation, respectively). Figure 4 illustrates the relation between these two masses for

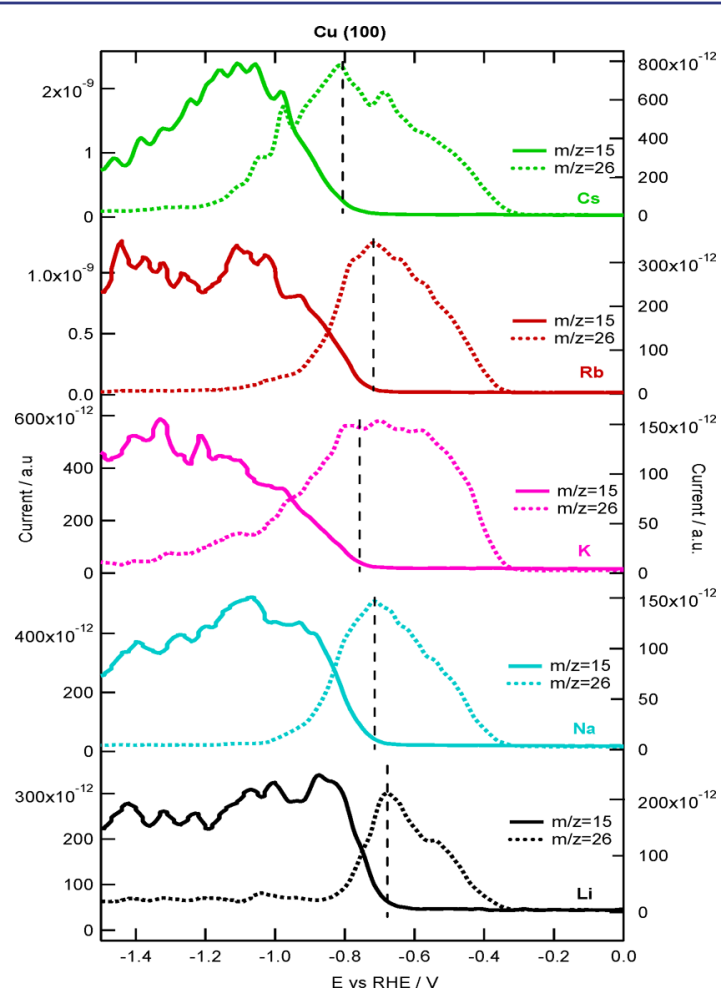

Figure 4. OLEMS mass fragments associated with the reduction products formed during $\mathrm{CO}$ reduction on a $\mathrm{Cu}(100)$ electrode in different $0.1 \mathrm{M}$ alkaline hydroxide solutions. Dashed lines correspond to $m / z=26$ associated with the formation of ethylene, plotted against the right axis, and solid lines correspond to $m / z=15$ associated with the formation of methane, plotted against the left axis. Vertical lines highlight the potential at which the $m / z=26$ signal associated with ethylene starts to decay.

the specific case of $\mathrm{CO}$ reduction on $\mathrm{Cu}(100)$, although the trend is also observable for $\mathrm{Cu}(111)$ and polycrystalline $\mathrm{Cu}$ (see Figure S5 in the SI). Importantly, the mass fragment associated with the formation of ethylene drops when the signal associated with the formation of methane starts to rise. Moreover, the $m / z=15$ signal increases faster in the electrolytes for which the $m / z=26$ signal decreases faster, leading to a delay in the potential where the maximum current for methane is observed, depending on the size of the cation. For example, while the decay in ethylene formation in $\mathrm{LiOH}$ is acute and the rise of the mass fragment associated with methane is steep, in $\mathrm{CsOH}$ solutions the decay of ethylene and the formation of methane are both more gradual. In this order of ideas, larger cations enhance the selectivity toward $\mathrm{C}_{2} \mathrm{H}_{4}$ over a wider potential range.

This behavior could be understood if, for instance, methane formation would be the result of $\mathrm{C}_{2} \mathrm{H}_{4}$ reduction. However, we discarded this hypothesis because ethylene reduction experiments did not lead to the formation of methane (see Figure S6). It is also important to note that ethane was not detected as a reduction product of ethylene in these experiments.
Therefore, we believe that a cation-, potential-, and facetdependent picture such as the one in Figure 5 is needed to

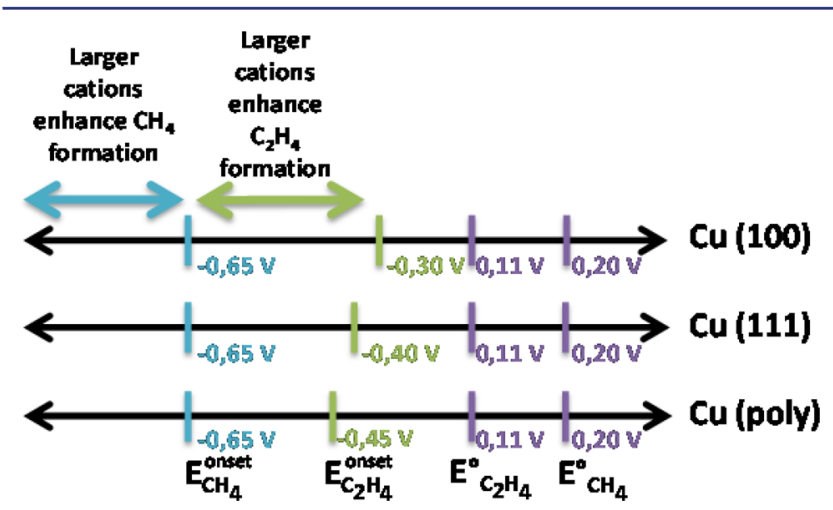

Figure 5. Schematics of the structure- and potential-dependent cation effects for $\mathrm{CO}$ reduction toward methane and ethylene in alkaline hydroxide electrolytes $(\mathrm{pH}=13)$. Potentials vs RHE. $E^{0}$ are standard equilibrium potentials.

portray the mechanistic effects of alkaline cations on $\mathrm{CO}$ reduction. The figure shows a schematic representation of the structure- and potential-dependency of the cation effects for $\mathrm{CO}$ reduction toward the two main products, methane and ethylene. The onset potential for ethylene formation depends on the facet, being lower for copper single crystals than for polycrystalline copper. In addition, the onset potential for ethylene is not affected by the cation nature when $\mathrm{CO}$ reduction is performed on copper single crystals (see Figure S7), whereas on polycrystalline copper the onset potential varies alongside the cation size, being $-0.6 \mathrm{~V}$ for $\mathrm{Li}^{+}$and $\mathrm{Na}^{+}$, $-0.4 \mathrm{~V}$ for $\mathrm{K}^{+}$, and $-0.35 \mathrm{~V}$ for $\mathrm{Rb}^{+}$and $\mathrm{Cs}^{+}$. On the other hand, the onset potential for methane formation is independent of both cation size and surface structure. In the range from -0.3 to $-0.65 \mathrm{~V}$, larger cations enhance the formation of ethylene, whereas at potentials more negative than $-0.65 \mathrm{~V}$ the formation of methane is favored. Figure 4 suggests that this phenomenon is due to a shutting down of the $C_{2}$ pathway at large overpotentials in which the $\mathrm{C}_{1}$ pathway becomes favorable.

Hori et al. explained the differences in product distribution on the nature of the cation based on the potential distribution at the electrode surface in terms of changes in the outer Helmholtz plane potential. ${ }^{10}$ The OHP potential varies with the cations according to their particular adsorption features. Specific adsorption of cations supposedly shifts the OHP potential to more positive values, the OHP potential being higher for $\mathrm{Cs}^{+}$than for $\mathrm{Li}^{+}$in view of their dissimilar hydration shells. In this model, a more negative OHP potential translates into a higher $\mathrm{H}^{+}$concentration, such that the $\mathrm{pH}$ at the electrode will decrease as the size of the cation decreases. At higher $\mathrm{pH}$ values the formation of ethylene vs methane is enhanced.

On the other hand, in the model proposed by Bell et al. ${ }^{21}$ for the cation enhancement of $\mathrm{CO}_{2}$ reduction, the $\mathrm{pH}$ near the electrode is lower when larger cations are in solution, leading to a higher local $\mathrm{CO}_{2}$ concentration that results into a higher cathodic activity. They attribute the decrease of $\mathrm{pH}$ when larger cations are present to a decrease of the $\mathrm{p} K_{\mathrm{a}}$ for the cations' hydrolysis. When the $\mathrm{p} K_{\mathrm{a}}$ is sufficiently low, hydrated cations serve as buffering agents, decreasing the $\mathrm{pH}$ near the electrode and thereby increasing the local concentration of $\mathrm{CO}_{2}$. Note 
that this model is in agreement with experimental data for potentials lower than $-1.1 \mathrm{~V}$ vs RHE. However, this model cannot explain the fact that similar cation effects are observed during CO reduction, ${ }^{10}$ the concentration of which is not affected by (local) $\mathrm{pH}$. In their model, Bell et al. explained that the hydrolysis of hydrated cations is only effective in mildly basic or acidic electrolytes. However, our experimental results showed a cation enhancement for the production of ethylene during $\mathrm{CO}$ reduction in strongly alkaline media $(\mathrm{pH}=13)$.

Our explanation of cation effects is based on Figures 3, S11, and S12. We believe that cations are essentially catalytic promoters, their presence altering substantially the free-energy landscape of $\mathrm{CO}$ reduction. They especially stabilize $\mathrm{C}_{2}$ species by means of strong $\mathrm{O}$-cation interactions, justified by the strong tendency of those species (e.g., * OCCO and $* \mathrm{OCCOH}$ ) to be negatively charged, unlike isolated *CO monomers. Our perspective on cation effects is in line with that of Janik and co-workers, ${ }^{37}$ who explicitly included cation, anion, and solvation effects in their calculations and reported similar effects for $\mathrm{CO}_{2}$ reduction in the presence of $\mathrm{K}^{+}$. The averaging in Figure 3 is close to that of Nørskov and co-workers, ${ }^{38,39}$ who have shown that cations at the double layer induce local field effects that alter the adsorption energies. Although overall cation effects can be averaged, we stress that subtle yet important details such as differences in adsorption sites, adsorption configurations (Figures S9 and S10), and onset potentials as a function of cation size (Figures S11 and S12) are only captured when modeling the cations explicitly.

Finally, it is important to note that the present work is devoted only to "fully metallic" $\mathrm{Cu}$ electrodes, while "oxidederived" Cu electrodes also exist and, due to their high activity for $\mathrm{CO}$ reduction, are the subject of extensive research. ${ }^{5,40-42}$ "Fully metallic" $\mathrm{Cu}(100)$ and oxide-derived $\mathrm{Cu}$ electrodes both produce large amounts of $\mathrm{C}_{2}$ products, although the former is inclined toward ethylene, while the latter favors ethanol. Our previous works provided a plausible explanation for such dissimilar behavior: there is a selectivity-determining intermediate in the $\mathrm{CO}$ reduction pathway to $\mathrm{C}_{2}$ products, namely, ${ }^{*} \mathrm{CH}_{2} \mathrm{CHO}{ }^{11}$ If hydrogenation leads to ${ }^{*} \mathrm{CH}_{3} \mathrm{CHO}$ (i.e., adsorbed acetaldehyde), ethanol is the major final product. ${ }^{12}$ Conversely, if hydrogenation leads to ${ }^{*} \mathrm{CH}_{2} \mathrm{CH}_{2} \mathrm{O}$, then ethylene is favored. ${ }^{11}$ Whereas acetaldehyde is reduced to ethanol at larger rates at steps and grain boundaries ${ }^{12,43}$ compared to terraces, pristine (100) terraces are known to favor ethylene production. ${ }^{8,9}$

\section{CONCLUSIONS}

In this paper, we have shown that the combined effect of alkaline cations and catalyst morphology can steer the selectivity of $\mathrm{CO}$ reduction toward ethylene or methane, depending on the potential. Specifically, our results suggest the following conclusions.

(1) In general, larger cations enhance $\mathrm{CO}$ reduction to ethylene at low overpotentials, especially on $\mathrm{Cu}(100)$. With smaller cations in solution, $\mathrm{CO}$ reduction on $\mathrm{Cu}(111)$ and $\mathrm{Cu}$ (polycrystalline) shows low selectivity for ethylene formation over methane over the whole potential range in which both species coexist. The formation of other minor $\mathrm{C}_{2}$ and $\mathrm{C}_{3}$ products (such as acetic acid, glycolic acid, ethanol, and propanol) is also enhanced by the presence of larger cations.

(2) A correlation between the decline of ethylene formation and the onset potential for methane formation was observed. Furthermore, methane formation reaches its plateau when ethylene formation drops to zero. This suggests that the $C_{2}$ pathway is blocked by the enhancement of the $C_{1}$ pathway. This correlation depends on the cation size, so that larger cations enhance the selectivity toward ethylene over a wider potential range.

(3) For the two major products, methane and ethylene, differences in the onset potential were found as a function of the cation size and the surface structure. While the onset potential of ethylene formation depends on these two factors, the onset potential of methane does not.

(4) FTIR and DFT calculations were used to gain insight into the origin of cation effects on $\mathrm{Cu}(100)$. As described elsewhere, ${ }^{26}$ FTIR suggests the presence of a hydrogenated dimer intermediate $(\mathrm{OCCOH})$ at low overpotentials. The formation of this intermediate depends on the size of the cation, so that the hydrogenated dimer can be detected with FTIR in the presence of $\mathrm{Li}^{+}, \mathrm{Na}^{+}$, and $\mathrm{K}^{+}$, but not in the presence of $\mathrm{Rb}^{+}$or $\mathrm{Cs}^{+}$. DFT calculations explain that the potential necessary to form $* \mathrm{OCCOH}$ from $* \mathrm{CO}$ in the presence of $\mathrm{Cs}^{+}$is more negative compared to $\mathrm{Li}^{+}$or $\mathrm{Na}^{+}$. Besides, the adsorption energies of species containing $\mathrm{C}-\mathrm{C}$ bonds are dramatically stabilized by cations with respect to $\mathrm{C}_{1}$ species, justifying the selectivity toward ethylene at low overpotentials.

(5) The role of cations in $\mathrm{CO}$ reduction is that of a catalytic promoter, changing the free energy landscape of $\mathrm{CO}$ reduction and specifically stabilizing certain intermediates, especially those with a favorable (electrostatic) interaction with the cation. Larger cations such as Cs promote pathways with these intermediates more effectively than smaller cations such as $\mathrm{Li}$.

\section{METHODS}

4.1. Experimental Section. Experimental methods are explained in detail in section S7 of the Supporting Information.

4.2. Computational. The DFT total energies were calculated with VASP, ${ }^{44}$ making use of the projector augmented wave (PAW) method $^{45}$ and the PBE exchange-correlation functional. ${ }^{46}$ Further details are provided in section S6 in the SI.

\section{ASSOCIATED CONTENT}

\section{S Supporting Information}

The Supporting Information is available free of charge on the ACS Publications website at DOI: 10.1021 /jacs.7b10142.

Hydrogen evolution reaction, HPLC measurements, ${ }^{1} \mathrm{H}$ NMR spectra, additional mechanistic implications, electrode surface characterization, additional computational details, experimental methods, exclusion of the formation of oxalates (PDF)

\section{AUTHOR INFORMATION}

\section{Corresponding Authors}

*f.calle.vallejo@chem.leidenuniv.nl

*m.koper@chem.leidenuniv.nl

ORCID $\odot$

Federico Calle-Vallejo: 0000-0001-5147-8635

Marc T. M. Koper: 0000-0001-6777-4594

\section{Present Address}

†Departament de Ciència de Materials i Química Fisica \& Institut de Química Teòrica i Computacional (IQTCUB), Universitat de Barcelona, Martí i Franqués 1, 08028 Barcelona, Spain. 


\section{Notes}

The authors declare no competing financial interest.

\section{ACKNOWLEDGMENTS}

F.C.V. acknowledges funding from NWO (Veni project number 722.014.009). The use of supercomputing facilities at SURFsara was sponsored by NWO Physical Sciences, with financial support by NWO. F.C.V. also thanks Spanish MEC for a Ramón y Cajal research contract (RYC-2015-18996).

\section{REFERENCES}

(1) Hori, Y. In Modern Aspects of Electrochemistry; Springer: New York, 2008; pp 89-189.

(2) Hori, Y.; Kikuchi, K.; Murata, A.; Suzuki, S. Chem. Lett. 1986, 15, 897-898.

(3) Hori, Y.; Kikuchi, K.; Suzuki, S. Chem. Lett. 1985, 14, 16951698 .

(4) Kuhl, K. P.; Cave, E. R.; Abram, D. N.; Jaramillo, T. F. Energy Environ. Sci. 2012, 5, 7050-7059.

(5) Roberts, F. S.; Kuhl, K. P.; Nilsson, A. Angew. Chem., Int. Ed. 2015, 54, 5179-5182.

(6) Li, C. W.; Ciston, J.; Kanan, M. W. Nature 2014, 508, 504-507.

(7) Hori, Y.; Takahashi, I.; Koga, O.; Hoshi, N. J. Mol. Catal. A: Chem. 2003, 199, 39-47.

(8) Schouten, K. J. P.; Pérez Gallent, E.; Koper, M. T. ACS Catal. 2013, 3, 1292-1295.

(9) Schouten, K. J. P.; Qin, Z.; Gallent, E. P.; Koper, M. T. M. J. Am. Chem. Soc. 2012, 134, 9864-9867.

(10) Murata, A.; Hori, Y. Bull. Chem. Soc. Jpn. 1991, 64, 123-127.

(11) Calle-Vallejo, F.; Koper, M. Angew. Chem., Int. Ed. 2013, 52, $7282-7285$

(12) Ledezma-Yanez, I.; Gallent, E. P.; Koper, M. T.; Calle-Vallejo, F. Catal. Today 2016, 262, 90-94.

(13) Li, H.; Li, Y.; Koper, M. T.; Calle-Vallejo, F. J. Am. Chem. Soc. 2014, 136, 15694-15701.

(14) Montoya, J. H.; Shi, C.; Chan, K.; Nørskov, J. K. J. Phys. Chem. Lett. 2015, 6, 2032-2037.

(15) Hori, Y.; Takahashi, R.; Yoshinami, Y.; Murata, A. J. Phys. Chem. B 1997, 101, 7075-7081.

(16) Gattrell, M.; Gupta, N.; Co, A. J. Electroanal. Chem. 2006, 594, $1-19$.

(17) Peterson, A. A.; Abild-Pedersen, F.; Studt, F.; Rossmeisl, J.; Nørskov, J. K. Energy Environ. Sci. 2010, 3, 1311-1315.

(18) Varela, A. S.; Ju, W.; Reier, T.; Strasser, P. ACS Catal. 2016, 6, 2136-2144.

(19) Lee, S.; Kim, D.; Lee, J. Angew. Chem. 2015, 127, 14914-14918.

(20) Kyriacou, G.; Anagnostopoulos, A. J. Appl. Electrochem. 1993, $23,483-486$.

(21) Singh, M. R.; Kwon, Y.; Lum, Y.; Ager, J. W., III; Bell, A. T. J. Am. Chem. Soc. 2016, 138, 13006-13012.

(22) Schouten, K. J. P.; Gallent, E. P.; Koper, M. T. J. Electroanal. Chem. 2013, 699, 6-9.

(23) Wuttig, A.; Surendranath, Y. ACS Catal. 2015, 5, 4479-4484.

(24) Hori, Y.; Takahashi, R.; Yoshinami, Y.; Murata, A. J. Phys. Chem. B 1997, 101, 7075-7081.

(25) Birdja, Y. Y.; Koper, M. T. M. J. Am. Chem. Soc. 2017, 139, 2030-2034.

(26) Pérez-Gallent, E.; Figueiredo, M. C.; Calle-Vallejo, F.; Koper, M. Angew. Chem. 2017, 129, 3675-3678.

(27) Hori, Y.; Koga, O.; Watanabe, Y.; Matsuo, T. Electrochim. Acta 1998, 44, 1389-1395.

(28) Ryberg, R. Surf. Sci. 1982, 114, 627-641.

(29) Gajdoš, M.; Hafner, J. Surf. Sci. 2005, 590, 117-126.

(30) Chang, S. C.; Weaver, M. J. J. Phys. Chem. 1990, 94, 5095-5102.

(31) Arán-Ais, R. M.; Figueiredo, M. C.; Vidal-Iglesias, F. J.; Climent, V.; Herrero, E.; Feliu, J. M. Electrochim. Acta 2011, 58, 184-192.

(32) Shaw, S. K.; Berná, A.; Feliu, J. M.; Nichols, R. J.; Jacob, T.; Schiffrin, D. J. Phys. Chem. Chem. Phys. 2011, 13, 5242-5251.
(33) Koper, M. T.; van Santen, R. A. J. Electroanal. Chem. 1999, 476, $64-70$.

(34) Cook, R. L.; MacDuff, R. C.; Sammells, A. F. J. Electrochem. Soc. 1989, 136, 1982-1984.

(35) DeWulf, D. W.; Jin, T.; Bard, A. J. J. Electrochem. Soc. 1989, 136, $1686-1691$.

(36) Hori, Y.; Murata, A.; Takahashi, R.; Suzuki, S. J. Am. Chem. Soc. 1987, 109, 5022-5023.

(37) Akhade, S. A.; McCrum, I. T.; Janik, M. J. J. Electrochem. Soc. 2016, 163, F477-F484.

(38) Sandberg, R. B.; Montoya, J. H.; Chan, K.; Nørskov, J. K. Surf. Sci. 2016, 654, 56-62.

(39) Chen, L. D.; Urushihara, M.; Chan, K.; Nørskov, J. K. ACS Catal. 2016, 6, 7133-7139.

(40) Kim, Y.-G.; Javier, A.; Baricuatro, J. H.; Soriaga, M. P. Electrocatalysis 2016, 7, 391-399.

(41) Verdaguer-Casadevall, A.; Li, C. W.; Johansson, T. P.; Scott, S. B.; McKeown, J. T.; Kumar, M.; Stephens, I. E.; Kanan, M. W.; Chorkendorff, I. J. Am. Chem. Soc. 2015, 137, 9808-9811.

(42) Gao, D.; Zegkinoglou, I.; Divins, N. J.; Scholten, F.; Sinev, I.; Grosse, P.; Roldan Cuenya, B. ACS Nano 2017, 11, 4825-4831.

(43) Bertheussen, E.; Verdaguer-Casadevall, A.; Ravasio, D.; Montoya, J. H.; Trimarco, D. B.; Roy, C.; Meier, S.; Wendland, J.; Nørskov, J. K.; Stephens, I. E. Angew. Chem., Int. Ed. 2016, 55, 14501454.

(44) Kresse, G.; Furthmüller, J. Phys. Rev. B: Condens. Matter Mater. Phys. 1996, 54, 11169-11186.

(45) Kresse, G.; Joubert, D. Phys. Rev. B: Condens. Matter Mater. Phys. 1999, 59, 1758-1775.

(46) Perdew, J. P.; Burke, K.; Ernzerhof, M. Phys. Rev. Lett. 1996, 77, $3865-3868$. 